\title{
Uso de objetos educacionais digitais para ensinar sistemas do corpo humano em uma escola do campo
}

\author{
Silvio Ferreira dos Santos $^{1}$, Marcelo Franco Leão ${ }^{2}$ \\ ${ }^{1}$ Instituto Federal de Mato Grosso - IFMT. Campus Confresa. Departamento de Ensino do Campus Confresa / \\ Pós-Graduação em Educação do Campo. Avenida Vilmar Fernandes, 300, Santa Luzia. Confresa - MT. \\ Brasil.silvio_f_santos@ hotmail.com. ${ }^{2}$ Instituto Federal de Mato Grosso - IFMT.
}

RESUMO. O estudo teve como objetivo avaliar o uso de softwares educacionais e aplicativos em dispositivos móveis para ensinar sistemas do corpo humano em uma escola do campo. Trata-se de uma pesquisa-ação, de abordagem qualitativa, desenvolvida em 2016 e que envolveu 14 estudantes do $8^{\circ}$ ano do Ensino Fundamental da Escola Estadual Sol Nascente, de Confresa-MT. O software e aplicativo escolhidos foram o Atlas do Corpo Humano e Sistemas do Corpo Humano $3 \mathrm{D}$, respectivamente, com ênfase nos sistemas digestório e circulatório. Os resultados do pré e pós teste, constituídos por 20 questões, corroboram a hipótese de que o uso de objetos educacionais digitais beneficia o processo educativo. Os estudantes aprenderam melhor os sistemas comparados a quando se utilizou apenas recursos tradicionais, como o livro didático. Esse avanço pode estar atrelado ao fato de os recursos utilizarem imagens em 3D e pontuarem cada parte do corpo, além de fornecer importantes informações e curiosidades sobre $\mathrm{o}$ assunto. Portanto, espera-se que as tecnologias digitais possam, cada vez mais, serem inseridas e exploradas nas práticas pedagógicas, pois esses recursos possibilitam estudar e tirar dúvidas, ampliando o tempo e os espaços educativos.

Palavras-chave: Ferramentas Tecnológicas, Recursos Didáticos, Ensino de Ciências. 


\title{
Using digital educational objects to teach human body systems at a countryside school
}

\begin{abstract}
The purpose of this study is to assess the use of educational software and mobile device applications to teach about the human body at a rural school. It is an action research, with a qualitative approach, developed in 2016 and involving 14 students from the 8th year Elementary Education at the Escola Estadual Sol Nascente in Confresa-MT. The chosen software and application was the Human Body Atlas and 3D Human Body Systems, emphasizing on the digestive and circulation systems. The results from the pre-and post-test, which comprised 20 questions together, corroborate the hypothesis that the use of digital educational objects benefits the education process. Students learned better the systems in comparison with when only traditional resources, such as a didactic book, was used. Such advancement could be harnessed to the fact that the resources make use of 3D images and point out each part of the body, besides providing important information and curiosities about the subject. It is therefore expected that digital technologies may be increasingly inserted and explored in pedagogical practices, since those resources allow for studying and solving queries, by broadening educational space and time.
\end{abstract}

Keywords: Technological Tools, Didactic Resources, Teaching Sciences. 


\section{Uso de objetos educativos digitales para enseñar sistemas del cuerpo humano en una escuela del campo}

RESUMEN. El estudio tuvo como objetivo evaluar el uso de software educativo y aplicaciones en dispositivos móviles para enseñar sistemas del cuerpo humano en una escuela del campo. Se trata de una investigación-acción, de abordaje cualitativo, desarrollada en 2016 y que involucró a 14 estudiantes del $8^{\circ}$ año de la Enseñanza Fundamental de la Escuela Estadual Sol Nascente, de Confresa-MT. El software y la aplicación elegidos fueron el Atlas del Cuerpo Humano y Sistemas del Cuerpo Humano 3D, respectivamente, con énfasis en los sistemas digestivo y circulatorio. Los resultados del pre y post test, constituidos por 20 preguntas, corroboran la hipótesis de que el uso de objetos educativos digitales beneficia el proceso educativo. Los estudiantes aprendieron mejor los sistemas comparado a cuando se utilizó sólo recursos tradicionales, como el libro didáctico. Este avance puede estar vinculado al hecho de que los recursos utilizan imágenes en 3D y puntualizan cada parte del cuerpo, además de proporcionar importantes informaciones y curiosidades sobre el tema. Por lo tanto, se espera que las tecnologías digitales puedan, cada vez más, ser insertadas y explotadas en las prácticas pedagógicas, pues estos recursos posibilitan estudiar y sacar dudas, ampliando el tiempo y los espacios educativos.

Palabras clave: Herramientas Tecnológicas, Recursos Didácticos, Enseñanza de las Ciências. 


\section{Introdução}

O uso das Tecnologias Digitais de Informação e Comunicação (TDIC) vem cada dia mais se fazendo presente no universo da sociedade contemporânea. Assim, diante dos avanços da ciência e da tecnologia, se torna impossível dissociar os processos de ensino e aprendizagem das evoluções tecnológicas presentes na sociedade, inclusive no ambiente escolar (Santos \& Leão, 2016). Esse fato demonstra a necessidade das escolas acompanharem as inovações e dos professores se atualizarem para utilizar as novas estratégias e recursos em suas aulas e assim criar um ambiente oportuno de aprendizagens para os estudantes.

Para Auler (2003), esse processo educativo, aportado na ciência e na tecnologia, será emancipatório se propiciar aos estudantes uma leitura crítica do mundo ao qual estão inseridos, relacionado ao desenvolvimento científico-tecnológico contemporâneo e que desenvolva ações no sentido de transformação dessa sociedade. Ou seja, é preciso extrair dos conceitos e recursos, aplicabilidade para a vida, utilizar saberes proporcionado pela ciência e pela tecnologia na resolução de problemas do cotidiano.

Frente a essa nova conjuntura educacional, se torna evidente que as escolas do campo também possam estar atentas às mudanças tecnológicas e que os professores que atuem nessa modalidade procurem se atualizar ao universo da comunicação e informação e que possa assim possibilitar aos estudantes o acesso às novas ferramentas pedagógicas para auxiliar na produção de novos conhecimentos.

Assim, de acordo com Moura (2009, p. 50): “O acesso a conteúdo multimídia deixou de estar limitado a um computador pessoal $(\mathrm{PC})$ e estendeu-se também às tecnologias móveis (telemóvel, PDA, Pocket PC, Tablet PC, Notebook)". Em outras palavras, a autora diz que o acesso à multimídia vem proporcionando um novo paradigma educacional, o móbile learning ou aprendizagem móvel, por meio de dispositivos móveis, sendo capaz de influenciar diretamente nas práticas educacionais.

Fonseca (2014) aponta que no Brasil há mais aparelhos celulares do que habitantes. Com isso, fica evidente a grande necessidade de fomentar a disseminação do uso desses dispositivos para serem utilizados como instrumentos pedagógicos, uma vez que a maioria dos estudantes tem acesso a esses aparelhos, facilidade em seu manuseio e os levam para o ambiente escolar. 
Nessa perspectiva, o uso destes dispositivos móveis como suporte pedagógico em sala de aula importante para o processo educativo, uma vez que a maioria dos estudantes dispõe desses aparelhos. O uso dessas ferramentas permitirá que o processo educativo seja favorecido, além de permitir que a escola e as aulas se tornem espaços atrativos para os estudantes, tornando-os partes integrantes e indispensáveis na construção de seus saberes.

Frente à problemática apresentada, o objetivo principal desse estudo é descrever e avaliar a utilização de softwares educacionais e aplicativos para dispositivos móveis com o intuito de ensinar os sistemas digestório e circulatório em uma turma do $8^{\circ}$ ano do Ensino Fundamental da Escola Estadual Sol Nascente, de Confresa-MT. Por meio do uso de tais ferramentas, foram ministrados os conteúdos em sala de aula de maneira que estivessem relacionados com o cotidiano do estudante.

Cabe aqui ressaltar que nem sempre iniciativas que envolvem tecnologias são possíveis de serem realizadas nesses espaços educativos. Muitas vezes, o professor tem a pré-disposição em desenvolver trabalhos como esse, porém o cenário encontrado em muitas escolas do campo não permite ocorrer essas experiências, pois algumas sequer tem energia elétrica e tampouco as ferramentas tecnológicas para desenvolver tais ações.

\section{Discursos teóricos sobre o uso de tecnologias no ensino}

Ao fazermos uma reflexão sobre o termo tecnologia móvel, surge o questionado sobre como se deu sua origem e seu uso, e compreender onde surgiu e quais foram as reais necessidades para sociedade daquela época. Nesse sentido, Silva (2002, p. 1) explicita que "O uso do termo tecnologia, oriundo da Revolução Industrial no final do Século XVIII, tem sido generalizado para outras áreas do conhecimento, além dos setores das indústrias têxtil e mecânica". Nesse aspecto, é possível perceber que desde seu surgimento, a tecnologia está presente em diversos ambientes, fazendo com que os meios de produção e informação se atualizem constantemente.

Ao considerar as alterações nos meios sociais devido ao constante uso das novas tecnologias, diversas pesquisas têm demonstrado o quanto é possível perceber que as novas tendências tecnológicas têm influenciado diretamente na vida cotidiana. Entretanto, as autoras Saboia, Vargas e Viva (2013) explicitam que vivenciamos a transição da Era da Informação para a Era do Conhecimento, sendo necessário que o 
processo educativo seja ampliado, enfrentando os novos desafios para melhorar as suas práticas pedagógicas adequando-as à realidade e necessidade educacional.

Diante do desafio atual do uso constante de tecnologias pelos estudantes e professores, fica evidente que novas pesquisas sejam realizadas para que possam aplicar e ao mesmo tempo possibilitar uma análise sobre as Tecnologias Digitais de Informação e Comunicação (TDIC) que estão presentes no cotidiano da sociedade, tornando-as imprescindíveis no ambiente educacional.

Neste contexto, Sodré (2012) ressalta que o uso das TDIC leva o professor a repensar sua função, a qual deixa de ser um detentor de saberes e passa a ser o de motivador de aprendizagens, que aponte caminhos para que os próprios estudantes possam compreender e atribuir significado aos objetos de seus estudos. Para o autor é necessário romper com alguns paradigmas tradicionais para que o professor seja mais um elo de ligação entre as TDIC e os estudantes, e dessa forma esses novos métodos/ferramentas sejam aceitos e trabalhados para contribuir na prática educacional docente.

Ainda segundo o autor supracitado, o papel do professor como educador permanece, mas agora como um orientador que direciona, facilita e significa $o$ processo de aprendizagem dos estudantes. Nesse sentido, as TIC não poderiam ser vistas com o papel de substituir o professor, mas de tornar significativos os mais variados métodos e práticas pedagógicas no processo de ensino e de aprendizagem.

Para Freire e Guimarães (2012), a apropriação dos meios de comunicação com fins de ensino e aprendizagem é perfeitamente possível e benéfica, sejam estes analógicos ou digitais. Os dispositivos móveis podem realmente fazer a diferença nas práticas pedagógicas, porém, para que isso ocorra, o professor deve estar preparado para usá-los como uma ferramenta, diferencial para aplicabilidade em sala de aula.

Dessa forma, faz-se necessário que profissionais da educação estejam preparados para realizar as mudanças em seus métodos didáticos incorporando os meios tecnológicos como instrumentos de comunicação e informação no espaço escolar. Nesse sentido, Fonseca (2014) ressalta que a apropriação de dispositivos móveis requer habilidades, planejamento para que possa ser útil e assim representar um diferencial nos processos pedagógicos.

No sentido de fomentar cada dia mais o uso das novas tecnologias na educação, alguns teóricos ressaltam que: 
O uso das tecnologias da Informação e Comunicação Móveis e Sem Fio (TIMS) aumentam os desafios da realidade escolar. Educadores precisam se adequar a realidade desenhada pelas TIMS. Entre as TIMS, temos o celular, um aparelho popular, com aplicativos que podem vir a ser utilizados em sala de aula como recurso pedagógico (Bento \& Cavalcante, 2013, p. 114).

Em outras palavras, o educador precisa ter consciência de que as escolhas de tecnologias educacionais estão vinculadas à concepção de conhecimento que ele próprio concebe. Outro aspecto a ser considerado é que os dispositivos móveis estão presentes em vários ambientes sociais, favorecendo o constante uso de aplicativos e possibilitando o frequente acesso à internet em qualquer lugar em que o sujeito se encontra. Sejam, crianças, jovens, adultos e pessoas da terceira idade, todos fazem uso de um aparelho celular ou smartphone para diversas funções do seu dia a dia, ou seja:

A tecnologia antes vista como algo que tirava o sujeito do convívio social e do contato coletivo, torna-se cada vez mais customizadora, assim os ambientes tornam-se individualizados, mas não individualizados. Os dispositivos, os aplicativos e suas interfaces podem ser cada vez mais customizados e personalizados. Os ambientes ganham fotos, perfis e avatares criando uma atmosfera mais humanizada, representando um ponto muito positivo para a pedagogia centrada no aluno (Totti et al., 2011, p. 2).

Nos dias atuais é indiscutível o crescente uso de diversos aplicativos instalados nos dispositivos móveis. Nesse sentido, Bento e Cavalcante (2013, p. 3) ressaltam que "mediante as facilidades da utilização de diferentes aplicativos no celular, fica nítida para nós a possibilidade de sua utilização em sala de aula: desde a calculadora ao acesso de bibliotecas virtuais".

Em outras palavras, as possibilidades são ampliadas quando se utiliza os aparelhos móveis a favor do processo educativo. Além dos recursos tradicionalmente disponíveis nessas TIMS, como calculadora, mídia player e outros, é possível acessar, via rede (internet), uma infinidade de sites e objetos educacionais de aprendizagem disponíveis sobre o assunto em estudo.

Esses objetos educacionais, segundo Tarouco, Fabre e Tamusiunas (2003) e Ruas (2012) são recursos didáticos suplementares que servem para dar suporte ao ensino. São exemplos de alguns objetos educacionais digitais: hipertextos, simulações, softwares, aplicativos, animações, vídeos, objetos de aprendizagem, mapas, experimentos práticos e imagens. Esses recursos digitais, elaborados a partir de uma base 
tecnológica, são dinâmicos e interativos, podendo ser perfeitamente reutilizados em sala de aula graças à disponibilidade das TDIC nas escolas.

De acordo com Lopes et al. (2015), os diferentes recursos possibilitados pelas TDIC possibilitam não apenas utilizar os objetos de aprendizagem em sala de aula, como também realizar adaptações desses materiais para o contexto no qual estão sendo utilizados. As autoras ressaltam que congregar diferentes mídias no ensino possibilita que os estudantes interajam diretamente com o objeto estudado, a exemplo do estudo que realizaram com estudantes com deficiência e/ou com dificuldades de aprendizagem.

Nesse aspecto, os pesquisadores Saboia, Vargas e Viva (2013) salientam que os objetos educacionais digitais possibilitam o desenvolvimento de novas atividades educacionais, novas maneiras de estabelecer relações interpessoais, além de ampliar o espaço físico e a abrangência do processo de ensino e aprendizagem. Com a utilização das TIMS são ampliadas as possibilidades de interação entre professor e estudante, assim como entre os próprios estudantes com seus pares, o que contribui para a construção de conhecimentos de maneira a tornar a sala de aula interativa, agradável e favorável à aprendizagem.

\section{Procedimentos metodológicos}

O presente estudo, baseado em Martins e Theóphilo (2007) e em Moreira (2011), configura-se como uma pesquisaação, cuja abordagem é qualitativa, pois implica um plano de ação com objetivo de mudança, de melhora frente a um problema identificado. Segundo Gil (2010), para que se possa avaliar a qualidade dos resultados de uma pesquisa, torna-se necessário saber como os dados foram obtidos e quais procedimentos foram adotados em sua análise e interpretação. É importante ressaltar que serão apresentados alguns dados numéricos, mas que os mesmos servirão apenas para confirmar os aspectos subjetivos desse processo de aprendizagem.

A utilização de objetos educacionais digitais tem como propósito promover aprendizagens quanto aos conceitos estudados. Thiollent (2009, p. 71) explica que "na pesquisa-ação, uma capacidade de aprendizagem é associada ao processo de investigação. Isto pode ser pensado no contexto das pesquisas em educação, comunicação, organização ou outras."

Nesse sentido, observa-se o cuidado em envolver os estudantes, no intuito de buscar e fomentar subsídios para o fortalecimento da aprendizagem. Segundo Thiollent (2009, p. 71), as "novas práticas 
pedagógicas têm que ser incorporada ao processo educacional, privilegiando ações que possam garantir a inclusão de novas tendências tecnológicas para $\mathrm{o}$ fortalecimento e manutenção do processo do ensino/aprendizagem".

Todas as ações tiveram a finalidade de promover a compreensão desses estudantes quanto aos sistemas digestório e circulatório do corpo humano em diferentes situações de aprendizagem. O intuito das ações foi analisar a utilização dos recursos tecnológicos no ensino de ciências, favorece $\mathrm{o}$ aprendizado dos estudantes em comparação com recursos didáticos convencionais, como o livro didático.

O lócus para desenvolver essa intervenção foi a Escola Estadual Sol Nascente, situada no Projeto de Assentamento (PA), Confresa Roncador, na Agrovila Lumiar, à distância de 45 km do centro urbano de Confresa, Estado do Mato Grosso. A instituição é considerada como escola do campo não somente por estar situada na zona rural, mas também por atender a populações do campo. O público para o qual as ações foram planejadas é composto por 14 (quatorze) estudantes de Ciências Naturais do Ensino Fundamental, do $3^{\circ}$ Ciclo, $8^{\circ}$ Ano. Todos eles são moradores da zona rural, cujas residências ficam em agrovilas próximas da escola.

Todos os estudantes participaram ativamente dessa pesquisa desenvolvida durante as aulas de Ciência Naturais sobre o corpo humano, mais precisamente o sistema circulatório e sistema digestório. Contudo, cabe mencionar que 1 (um) dos estudantes é portador de deficiência e que, por tal motivo, o mesmo participou das atividades coletivas, mas não conseguiu responder aos questionários aplicados.

Como instrumentos utilizados para coletar dados, foram utilizados questionários para avaliar a aprendizagem. A aplicação deles ocorreu em dois momentos: antes e depois da intervenção com ferramentas tecnológicas. Justifica-se utilizar esse procedimento devido à escola possuir apenas uma turma de $8^{\circ}$ ano, não tendo outra para servir de controle. O número de questões desses instrumentos foi 20 (vinte), sendo 10 sobre o sistema digestório e 10 sobre o circulatório. Foram questões objetivas de múltipla escolha.

Foram quatro as ações planejadas e desenvolvidas durante essa intervenção pedagógica, que foram registradas no diário de bordo. Em um primeiro momento, foi utilizado o livro didático de Ciências como recurso teórico no ensino dos conceitos sobre os sistemas digestório e circulatório. 
Nessas aulas, foram exploradas as informações contidas no livro com o intuito de que o estudante pudesse compreender cada etapa do sistema digestório, a formação do sistema circulatório, assim como sua importância para o funcionamento de corpo humano. Após as leituras dos textos e discussões em aula sobre $\mathrm{o}$ assunto, foi aplicado $\mathrm{o}$ questionário para avaliar a compreensão dos estudantes sobre os sistemas digestório e circulatório nessa situação convencional de ensino, utilizando como recurso apenas o livro didático.

Em um segundo momento foram apresentados e explorados de forma livre alguns recursos tecnológicos no estudo dos sistemas supracitados. A aula iniciou com a apresentação do software gratuito denominado "Atlas do Corpo Humano", sendo projetado por um projetor de multimídia. Nessa etapa, foi explicado como o software poderia ser explorado e os recursos disponíveis.

O software apresenta uma viagem interativa ao corpo humano, ou seja, um estudo aprofundado sobre o corpo humano. Para o desenvolvimento da aula, o software foi explorado de forma coletiva, por meio da projeção com projetor de multimídia e intermediado pelo professor, no sentido de direcionar as discussões sobre os conteúdos planejados.
Anteriormente foi solicitada a permissão da coordenação pedagógica da escola para que os estudantes utilizassem seus dispositivos móveis dento de sala de aula, a fim de ser disponibilizado a todos, o aplicativo "Sistemas do Corpo Humano 3D, ii. Dessa forma, os estudantes com o aplicativo devidamente instalado, puderam dar continuidade aos estudos do corpo humano por meio da exploração desse recurso, inclusive fora do horário de aula. $\mathrm{O}$ professor informou que em outro momento ocorreria uma atividade de aprendizagem. Foi solicitado que os estudantes registrassem em seus cadernos as informações julgadas mais importantes para servir de subsídio na atividade agendada.

No terceiro momento, foi desenvolvida uma atividade colaborativa, em que a turma foi dividida em 4 (quatro) grupos, sendo que dois deles continham quatro integrantes e os outros dois grupos com três integrantes cada. Os grupos responderam um questionário de avaliação da aprendizagem e tiveram igual período de execução. Esse instrumento também foi constituído por 20 questões (conforme apêndice 1). É importante esclarecer que todas as questões aplicadas foram extraídas do próprio software, com o mesmo nível de dificuldade. 
Depois dessa atividade, foi apresentado pelo professor outro recurso didático presente no software anteriormente citado, chamado "Jogo da Mente”. Esse recurso projetado em sala de aula apresenta questões de forma aleatória, contendo um tempo máximo de 15 (quinze) segundos para a resposta. $\mathrm{O}$ tempo é delimitado pelo software, respeitando cada nível de dificuldade (fácil, médio e difícil). Cabe aqui apontar que cada questão é objetiva e possui 3 (três) opções de respostas, sendo a letra A, B e C também objetivas. A atividade também foi desenvolvida pelos mesmos grupos.

Para agilizar o processo, o professor fez a leitura de cada questão, cabendo aos grupos o tempo determinado para interpretar a questão, discutir com seus colegas e escolher a opção que julgassem ser a correta. As respostas eram registradas em uma folha fornecida previamente no formato de cartão resposta. Após as 18 atividades respondidas, os grupos foram avaliados de acordo com as respostas certas e erradas apresentado pelo próprio software.
Ao término dessa intervenção, foi aplicado um questionário de avaliação das aulas, constituído por oito questões abertas. Para garantir o anonimato dos sujeitos da pesquisa, os nomes foram substituídos pelas siglas E 1 (estudante 1), E 2 (estudante 2), E 3 (estudante 3) e assim sucessivamente. A análise e discussão das respostas coletadas foram realizadas sob a luz do referencial teórico anteriormente citado.

\section{Resultados e discussões}

Como já foi mencionada anteriormente, a coleta de dados se deu por meio do questionário de avaliação da aprendizagem, que foi aplicado em dois momentos: antes do desenvolvimento das ações com ferramentas tecnológicas e após a conclusão das atividades. Na figura 1 é possível verificar o desempenho dos estudantes quanto à compreensão do sistema digestório, inicialmente com o livro didático (em azul) e depois com a utilização do software e aplicativo (em laranja). 
Figura 1: Aproveitamento referente ao estudo do Sistema Digestório.

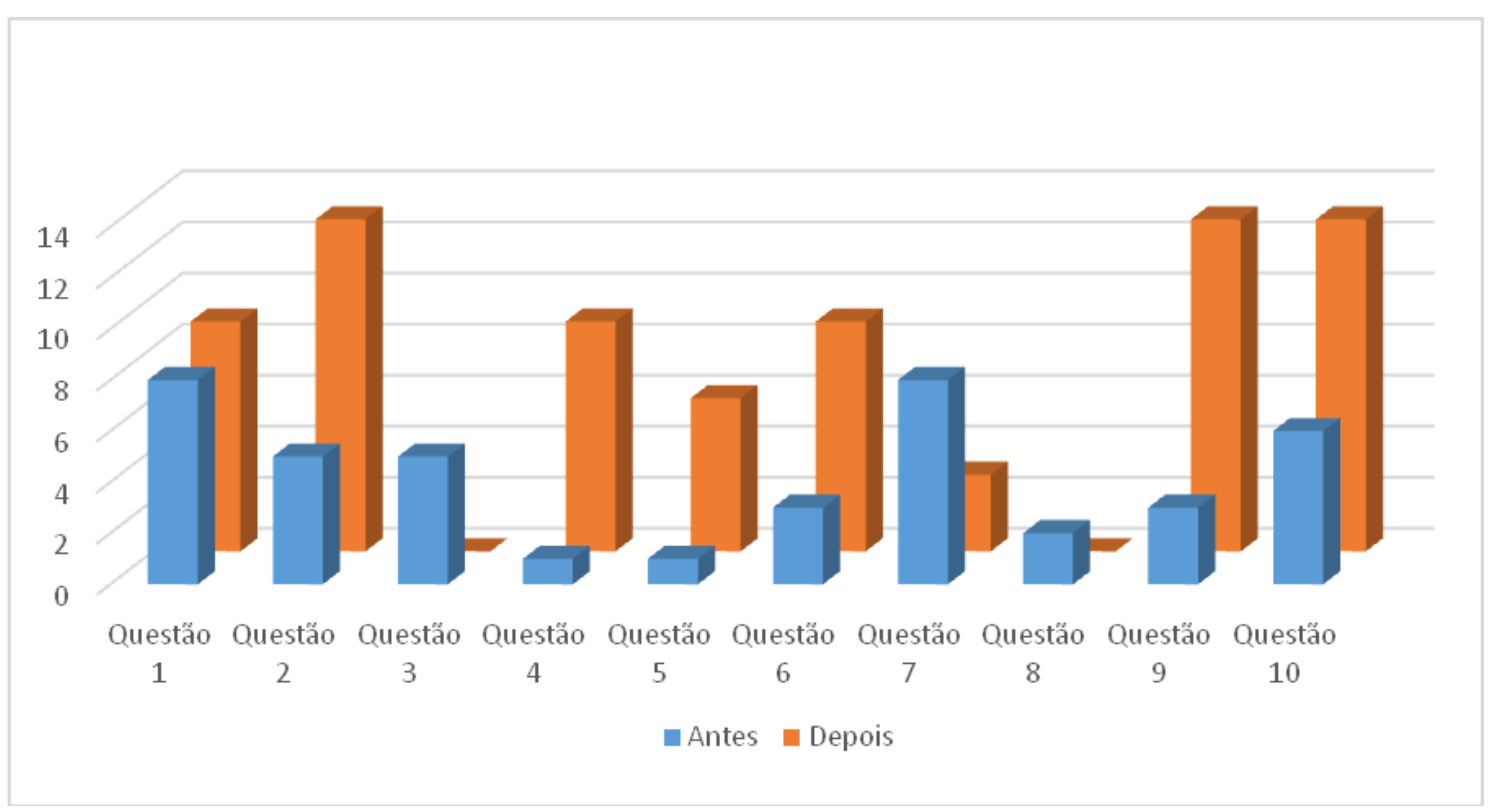

Fonte: Elaborado pelos autores (2016).

De acordo com os dados coletados, é possível verificar; por meio das questões de $n^{\circ} 1,2,4,5,6,9$ e 10 , que os 13 (treze) estudantes respondentes compreenderam melhor o sistema digestório com o uso de ferramentas tecnológicas e por isso tiveram maior número de acertos. Isso mostra que o uso de tais ferramentas pedagógicas é cada vez mais necessário no processo educativo.

Nesse sentido, Fonseca (2014, p. 5) afirma que "o uso de tecnologias como essas tem como princípio um ensinoaprendizagem anytime, anywhere". Em outras palavras, o autor defende uma aprendizagem móvel, diz que pode ocorrer em qualquer lugar e a qualquer hora.
Essa assertiva é corroborada com o aproveitamento constatado nesse estudo, pois o significativo aumento no número de acertos depois da utilização do software e do aplicativo demonstra que as ferramentas tecnológicas possibilitam a construção de aprendizagens, como defende Ruas (2012). Essa melhora pode estar atrelada ao fato de que os recursos utilizados trazem imagens em 3D de cada parte do corpo humano, além das características e funções do sistema digestório estudado.

Quando são explorados os recursos tecnológicos na escola, não só aqueles restritos aos computadores, o processo educativo se torna mais prazeroso $\mathrm{e}$ significativo tanto para os estudantes como para o professor, tornando esse momento 
formativo diferenciado da prática livro didático). De fato, as questões tradicional em que o professor é detentor supracitadas foram escolhidas do conhecimento e o livro didático é a intencionalmente em um nível mais única ferramenta utilizada (Moura, 2009). complexo, o que pode justificar tal

Ao analisar os dados, também foi possível verificar que apenas nas questões de $\mathrm{n}^{\mathrm{o}} 3,7$ e 8 foram obtidos um número de acertos baixo e ainda um pouco melhor desempenho. A seguir (Figura 2), é apresentado o desempenho dos estudantes quanto à compreensão do sistema circulatório.

antes da intervenção (somente utilizando o

Figura 2: Aproveitamento referente ao estudo do Sistema Circulatório.

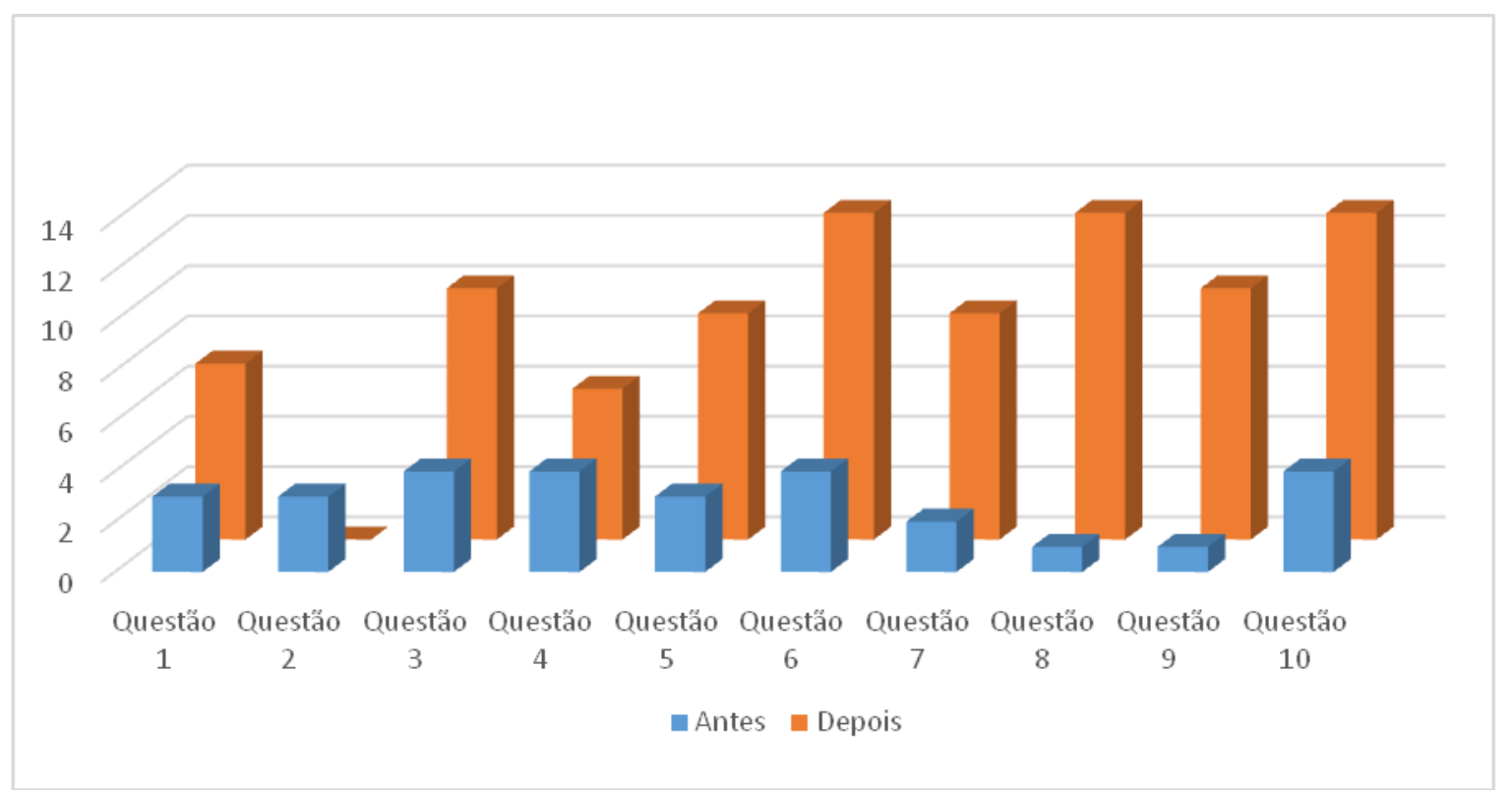

Fonte: Elaborado pelo autor da pesquisa (2016).

Ao analisarmos os dados referentes ao sistema circulatório, percebe-se que os estudantes também apresentaram melhor desempenho quando utilizaram ferramentas tecnológicas. Em todas as questões, exceto a de $\mathrm{n}^{\circ} 2$, o aumento no número de acertos foi significativo. Isso demonstra que os estudantes compreenderam melhor sobre o sistema circulatório após terem realizados estudos com o auxílio do software e do aplicativo.

Corroborando essa interpretação, Fonseca (2014, p. 6) confirma que:

Os atributos do uso dos celulares e smartphones para fins de ensinoaprendizagem são vários. $\mathrm{A}$ familiaridade, por ser considerada 
uma tecnologia comum no cotidiano e amigável, a mobilidade e portabilidade, que permite leva-lo para qualquer parte, os aspectos cognitivos, no contato com uma gama de recursos em vários formatos (texto, som, imagem, vídeo) e a conectividade, que amplia a comunicação, o acesso à informação e contribuí para a colaboração e compartilhamento, são atributos que podem ser colocados como potencializadores do aprendizado.

Diante do grande desafio em avançar no processo educacional no cenário brasileiro, torna-se evidente que os professores precisam utilizar novas ferramentas pedagógicas para que se possa atrair e ao mesmo tempo interagir com os estudantes. Cabe lembrar que Auler (2003) defende que a escola é a responsável por alfabetizar os cidadãos a fim de que sejam capazes de adaptar as conquistas científicas e tecnológicas na resolução de problemas cotidianos.

Quanto ao desempenho durante o jogo da mente, os quatro grupos acertaram $16,16,15$ e 14 questões respectivamente. Em um total de 18, pode-se considerar que os saberes compreendidos sobre os sistemas estudados. Esse jogo interativo permitiu que os estudantes testassem os conhecimentos construídos ao longo dos estudos e da exploração dos recursos tecnológicos desenvolvidos em sala de aula, de acordo com o próprio Thiollent (2009).
No sentido de buscar fazer uma avaliação quanto ao uso de ferramentas tecnológicas em sala de aula para estudar o sistema digestório e sistema circulatório, foram realizados alguns questionamentos junto aos estudantes e algumas das respostas foram trazidas para esse artigo.

Se consideram importante o uso das tecnologias a exemplo do software e do aplicativo utilizados em sala de aula:

"Sim, pois a tecnologia é uma excelente fonte para utilizar dentro da sala de aula" (E 3).

"Sim, para melhor entendimento dos conteúdos" (E 4).

Não foram apresentadas mais respostas devido todas expressarem que aprovam o uso de tecnologias para estudar. Utilizar TIMS na educação pode até ser desafiador como aponta Bento e Cavalcante (2013), porém é preciso que os professores explorem esse importante recurso pedagógico em sala de aula.

Quanto às contribuições do software e do aplicativo para a aprendizagem:

"Muito, para mim aprender o sistema circulatório e o sistema digestório, foi muito melhor pra mim aprender" (E 1).

"Ele contribuiu para nos ajudar a aprender mais. No sentido de nos ajudar a compreender os 
conteúdos com mais facilidade" (E 2).

"Contribuiu que eu aprendi mais com o aplicativo" (E 7).

Esse reconhecimento de que o acesso às tecnologias educacionais favorece a construção de aprendizagens corrobora o pensamento de Moura (2009), que defende que o acesso à multimídia, em especial às tecnologias móveis, é capaz de influenciar positivamente no processo educativo.

Se houve dificuldades em compreender os conteúdos ministrados com o software e ou em utilizá-lo:

"Não, foi bem mais fácil pra gente aprender, ele mostra as coisas com mais clarezas é fácil” (E1).

"Não, pois o software é excelente para estudar dentro da sala de aula" (E 3).

"Não, nem um pouco, o aplicativo foi excelente" (E 9).

Tais constatações nos levam a acreditar que os objetos educacionais digitais por meio das tecnologias utilizadas nesse estudo contribuíram para a interação dos conhecimentos científicos e tecnológicos com a vida cotidiana dos estudantes (Auler, 2003), devido ao caráter dinâmico e interativo desse suporte disponível ao ensino (Tarouco, Fabre \& Tamusiunas, 2003).
Sobre as potencialidades encontradas na utilização desses recursos tecnológicos:

"Foi excelente, teve muito mais aprendizado, mais discussão foi bem mais fácil que o livro, mostra bem mais clareza e mais participação dos alunos" (E 1).

"Foi excelente, teve dinâmica, a aprendizagem foi maior" (E 2).

"Melhor entendimento dos conteúdos com os aplicativos e nós podemos ver as ótimas imagens do coração, os órgãos" (E 4).

"Sim, para aprender mais que com o livro" (E 7).

Conforme Lopes et al. (2015), a utilização de objetos de aprendizagem no ensino e/ou sua adaptação não significa simplificar ou reduzir a complexidade dos conceitos estudados, mas sim criar novas possibilidades para que as aprendizagens sejam construídas.

Todos os estudantes que responderam a questão foram unânimes em considerar que uso de dispositivos móveis em outras disciplinas.

Sobre os pontos positivos e negativos na utilização dos mesmos como ferramentas pedagógicas no fortalecimento dos processos de ensino e aprendizagem: 
"Os pontos são todos positivos, porque dá para ver as imagens em três D” (E 3).

"Para mim não teve pontos negativos, só positivos porque o aplicativo é excelente" (E 8).

"O aplicativo não tem nada de ruim" (E 11).

As respostas confirmam que a utilização das TDIC é imprescindível no meio educacional, que os diferentes recursos possíveis por meio dessas tecnologias ampliam as possibilidades de interação, além de utilizar uma linguagem envolvente e motivadora (Lopes et al., 2015; Saboia, Vargas \& Viva, 2013).

Sobre a interação dos estudantes pelos estudos comparando ferramentas tradicionais (livro didático) e tecnologias digitais (smatphone):

"O aplicativo porque mostra a imagem em três $\mathrm{D}$, muito melhor e mostra as coisas com mais clarezas" (E 1).

“O dispositivo é mais avançado, nos livros é uma dificuldade os professores passam de vez enquanto eles passam 2 capítulos, e nos dispositivos é excelente e facilita para os estudos" (E 4).
"O smartphone, porque foi melhor para entender, já o livro também aprendi, mas é mais difícil" (E5).

"No livro é mais ruim, porque não mostra as imagens que nós queremos ver" (E 7).

De acordo com as respostas dos estudantes sobre o uso de aplicativos instalados nos dispositivos móveis para estudar os sistemas digestório e circulatório, foi possível analisar que a maioria apontou os dispositivos móveis como uma excelente ferramenta pedagógica para ser utilizada em várias disciplinas. Observa-se que os estudantes interagem e aprendem melhor em meio às tecnologias e que realmente é possível a aprendizagem móvel defendida por Moura (2009).

Realmente o desafio atual, apontado por Bento e Cavalcante (2013), parece estar relacionado à adequação dos professores e de suas práticas pedagógicas para com a realidade desenhada pelas TIMS, pois os estudantes de hoje agem com naturalidade no que diz respeito ao uso de tecnologias. Os autores também defendem que os diferentes aplicativos disponíveis nos aparelhos móveis são recursos que podem favorecer a construção de aprendizados com significado, desde que seja utilizado de maneira objetiva, a exemplo do que aconteceu nesta pesquisa. 


\section{Considerações finais}

Pelo estudo realizado é possível perceber a importância de os professores utilizarem meios e ferramentas pedagógicas como as TIMS, para ministrar conteúdos de diversas áreas do conhecimento, fazendo com que os estudantes possam interagir com as novas tendências tecnológicas que adentram no ambiente escolar.

Os resultados expressos tanto no pré e pós-teste sobre os sistemas digestório e circulatório, como no jogo da mente, comprovam que tais recursos incorporados nas práticas pedagógicas apresentam grande potencial para a construção de variados saberes. A avaliação realizada pelos estudantes envolvidos revela o quanto às tecnologias são atrativas e podem contribuir para a aprendizagem.

O uso de softwares e aplicativos nas mais variadas áreas do conhecimento tem demonstrado resultados positivos, uma vez que os estudantes sabem manusear essas tecnologias e muitas delas, como os smartphones, podem ser levadas a qualquer lugar, permitindo aos estudantes acessar os mais variados conceitos por meio de diferentes linguagens, desde imagens simples até gráficos mais complexos em 3D.
É preciso que os processos de ensino e de aprendizagem sejam mais que meros momentos de repasses de conteúdos de forma arcaica e não substanciada. Não se pode deixar de nos atualizar e direcionar os estudantes para um mundo cada vez mais digital e informatizado, pois é impossível vivermos sem acesso aos diversos meios de informação que permeiam a sociedade atual. Portanto, o uso de objetos educacionais digitais para ensinar Ciências Naturais é viável e contribui positivamente no processo educativo, conforme verificado no presente estudo.

\section{Referências}

Auler, D. (2003). Alfabetização científicotecnológica: um novo "paradigma"? Ensaio - Pesquisa em Educação em Ciências, 5(1), 68-83.

Bento, M. C. M., \& Cavalcante, R. S. (2013). Tecnologias Móveis em Educação: o uso do celular na sala de aula. ECCOM, 7(4), 113-120.

Fonseca, A. G. M. F. (2014). A ascensão dos dispositivos móveis e seus usos no ensino-aprendizagem. $\quad 1^{\mathrm{o}}$ Encontro Internacional de Tecnologia, Comunicação e Ciência Cognitiva. Ano II - Agosto de 2014. Anais. São Paulo.

Freire, P., \& Guimarães S. (2012). Educar com a mídia: novos diálogos sobre educação. Rio de Janeiro: Paz e Terra. 
Gil, A. C. (2010). Como elaborar projetos de pesquisa/Antonio Carlos Gil. (5 $\left.5^{\text {th }} \mathrm{ed}\right)$. São Paulo: Atlas.

Lopes, M. I., Rehfeldt, M. J. H., Bersch, M. E., \& Rosa, D. C. (2015). Tecnologia como potencializadora da inclusão no Ensino Superior. Caderno Pedagógico (Lajeado. Online), 12(1), 122-137.

Martins, G. A., \& Theóphilo, C. R. (2007). Metodologia da Investigação Científica para Ciências Sociais Aplicadas. São Paulo: Atlas.

Moreira, M. A. (2011). Metodologias de pesquisa em ensino. São Paulo: Editora Livraria da Física.

Moura, A. (2009). Geração Móvel: um ambiente de aprendizagem suportado por tecnologias móveis para a Geração Polegar. In P. Dias, A. J. Osório (Org.). VI Conferência Internacional de TIC na Educação Challenges, 2009/Desafios 2009. Actas. Braga: Universidade do Minho. 5078. Recuperado em 07 de novembro, 2016, de

repositorium.sdum.uminho.pt/bitstream/18 22/10056/1/Moura\%20(2009)\%20Challen ges.pdf

Ruas, P. A. A. R. (2012). A utilização do Banco Internacional de Objetos Educacionais para a formação de professores de Física do Ensino Médio no município de Santo André. 2012. Dissertação (Mestrado em Ensino). Universidade Federal do ABC. Santo André. Recuperado em 28 de setembro, 2016, de biblioteca.ufabc.edu.br/index.php?codigo $\underline{\text { sophia }=47227}$

Saboia, J., Vargas, P. L., \& Viva, M. A. A. (2013). O uso dos dispositivos móveis no processo de ensino e aprendizagem no meio virtual. Revista Cesuca Virtual: Conhecimento sem Fronteiras, 1(1), 1-13.
Santos, S. F., \& Leão, M. F. (2016). Uso de softwares educacionais e aplicativos para dispositivos móveis: Ferramentas para ensinar Ciências Naturais em escolas do campo. In $1^{\mathrm{a}}$ Mostra de Trabalhos dos Cursos de Especialização do IFMT Campus Confresa, 2016. Anais. ConfresaMT, 2016. Recuperado em 25 de janeiro, 2017 , de mostradetrabalhosespecializacoes.blogspot .com.br/p/blog-page_15.html

Silva, J. C. T. (2002). Tecnologia: conceito e dimensões. XXII Encontro Nacional de Produção. Curitiba, 2002. Anais. CuritibaPR, 2002. Recuperado em 16 de setembro, 2016,

de www.abepro.org.br/biblioteca/enegep2002 tr80_0357.pdf

Sodré, M. (2012). Reinventando a Educação: Diversidade, descolonização $e$ redes. Petrópolis: Editora Vozes.

Tarouco, L., Fabre, M. J. M., \& Tamusiunas, F. R. (2003). Reusabilidade de objetos educacionais. Revista Novas Tecnologias na Educação, 1(1), 1-11.

Thiollent, M. (2009). Metodologia da pesquisa-ação. São Paulo: Editora Autores Associados.

Totti, A. R.; Gomes, C.; Souza, W. G.; Moreira, S. P. T. (2011). M-Learning: Possibilidades para a Educação a Distância. In: $17^{\circ}$ Congresso Internacional ABED de Educação a Distância, 2011, Manaus. Anais. Manaus-AM, 2011. Recuperado em 18 de outubro, 2016, de www.abed.org..br/congresso2011/cd/181.p $\underline{\mathrm{df}}$ 


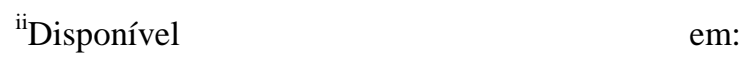
https://play.google.com/store/apps/details?id=com. EvoBooks.SistemasCorpoHumano\&hl=pt-BR

Recebido em: 21/06/2017

Aprovado em: 28/08/2017

Publicado em: 13/12/2017

Como citar este artigo / How to cite this article / Como citar este artículo:

APA:

Santos, S. F., \& Leão, M. F. (2017). Uso de objetos educacionais digitais para ensinar sistemas do corpo humano em uma escola do campo. Rev. Bras. Educ. Camp., $\quad 2(3), \quad 861-880 . \quad$ DOI: http://dx.doi.org/10.20873/uft.2525-

4863.2017v2n3p861

ABNT:

SANTOS, S. F.; LEÃO, M. F. Uso de objetos educacionais digitais para ensinar sistemas do corpo humano em uma escola do campo. Rev. Bras. Educ. Camp., Tocantinópolis, v. 2, n. 3, p. 861-880, 2017. DOI: $\quad$ http://dx.doi.org/10.20873/uft.2525$\underline{4863.2017 \mathrm{v} 2 \mathrm{n} 3 \mathrm{p} 861}$

\section{ORCID}

Silvio Ferreira dos Santos

http://orcid.org/0000-0001-7405-0535

Marcelo Franco Leão

http://orcid.org/0000-0002-9184-916X

Apêndice - Questões utilizadas antes e depois da intervenção pedagógica:

01 - Qual o peso aproximado do coração?
a) 80 gramas
b) 250 gramas
c) 1 quilo e meio

02 - A que órgão corresponde as veias hepáticas?
a) A hipófise
b) A hepatite

c) Ao fígado

03 - Por que não sentimos ao cortar o cabelo ou unhas?

a) Porque estas partes do corpo não dispõem de terminações nervosas

b) Porque estas partes do corpo não contêm sangue

c) Porque estas partes do corpo carecem de vida

04 - De que cor é o Plasma sanguíneo?
a) Vermelho
b) Amarelo
c) Azul

05 - Qual o nome das últimas ramificações das artérias, de dimensões microscópicas?
a)
Átomos
b) Arteríolas

c) Moléculas

06 - Como se chamam as artérias que percorrem os dedos das mãos?
a) Art
Artérias palmares
b) Artérias
terminais c) Artérias digitais

07 - Qual é o nome da artéria que irriga a língua?
a) Artéria sublingual
b) Artéria
lingual c) Artéria supralingual

08 - Quais são os três tipos de componentes sanguíneos existentes?

a) Glóbulos vermelhos, glóbulos brancos e nucleotídeos

b) Glóbulos vermelhos, glóbulos brancos e plaquetas

c) Glóbulos vermelhos, glóbulos brancos e aminoácidos

09 - O que são vênulas?

a) Veias com pouca irrigação sanguínea

b) Veia que se converteram em varizes

c) Veia de pequeno calibre

10 - Como é chamado o movimento de sangue realizado pelo interior do corpo?
a) Aferência
b) Circulação

c) Peristaltismo

11 - O intestino delgado é a estrutura mais longa do Sistema Digestório e mede:

a) Cerca de um metro e meio

b) Cerca de sete metros

c) Cerca de quinze metros

12 - Como se chama a massa de alimentos que desce em direção ao estômago? 

a) Comida
b) Bolo alimentar

c) Aporte calórico

13 - Por que o reto possui este nome?

a) Pela falta de rugosidade de suas paredes

b) Pelo seu formato quase reto

c) Pelo formato de seu processo

14 - Onde se localiza o intestino grosso?

a) Como continuação do intestino delgado

b) Como continuação da traqueia

c) Como continuação do reto

15 - Qual é um dos órgãos mais volumosos e com maior número de funções do corpo?
a) $\mathrm{O}$ esterno
b) A bexiga
c) $\mathrm{O}$ fígado

16 - Qual é o nome da parte do corpo que permite o ingresso das substâncias alimentícias?
a) Estômago
b) Tubo digestivo
c) Boca

17 - Qual é a função dos sucos gástricos?

a) Degradar os alimentos em elementos mais simples para que possam ser facilmente absorvidos.

b) Umedecer os alimentos para facilitar sua absorção

c) Eles simplesmente aceleram a digestão, sem nenhuma função específica

18 - A massa de alimento é também conhecida como?
a) Timo
b) Quima

c) Quimo

19 - Qual é o nome do processo realizado pelo Sistema Digestório?
a) Deglutição
b) Bolo

alimentar

c) Digestão

20 - Como se chama os restos descartados pelo processo de digestão?
a) Toxinas
b) Metabólitos
c) Fezes 